\title{
Uma abordagem histórico-antropológica do contato entre os Akwẽ-Xerente e a sociedade não indígena
}

\author{
A historical-anthropological approach of the contact \\ between the people Akwẽ-Xerente and the non indigenous \\ society
}

\author{
Poliene Soares dos Santos Bicalho ${ }^{1}$ \\ Márcia Machado²
}

DOI: http://dx.doi.org/10.20435/tellus.v18i35.479

\begin{abstract}
Resumo: Neste trabalho teórico, as autoras contextualizam a produção discursiva e historiográfica acerca da história indígena no Brasil. Em especial, ao tomarem como eixo norteador o diálogo necessário entre as áreas de História e Antropologia, buscam apontar possíveis diretrizes interpretativas para o desenvolvimento de pesquisas acerca das questões indígenas. Na reflexão teórica, destacam o conceito de longa duração, formulado por Fernand Braudel, para a compreensão da temática. A fim de demonstrar a efetividade da conceituação, propõem uma discussão do movimento indígena na história a partir da descrição dos processos históricos do contato interétnico da etnia Akwẽ-Xerente com parcelas da sociedade nacional.
\end{abstract}

Palavras-chave: História e Antropologia; indígenas Akwẽ-Xerente; políticas e legislação indigenistas; contatos interétnicos.

\begin{abstract}
In this theoretical work, the authors contextualize the discursive and historiographic production about the indigenous history in Brazil. In particular, when they take as a guide the necessary dialogue between the filds of History and Anthropology, they try to point possible interpretative guidelines for the development of research on indigenous issues. In the theoretical reflection they emphasize the concept of long duration, formulated by Fernand Braudel for the understanding of the thematic. In order to demonstrate the effectiveness of the conceptualization, they propose a discussion of indigenous movement in history from the description of the historical processes of the interethnic contact of the Akwẽ-Xerente ethnic group with parts of the national society.
\end{abstract}

Keywords: History and Anthropology; indigenous people Akwẽ-Xerente; policies and legislation indigenist; interethnic contacts.

\footnotetext{
${ }^{1}$ Universidade Estadual de Goiás (UEG), Anápolis, Goiás, Brasil.

${ }^{2}$ Universidade Federal do Tocantins (UFT), Miracema do Tocantins, Tocantins, Brasil.
} 
As sociedades indígenas de hoje não são portanto o produto da natureza, antes suas relações com o meio ambiente são mediatizadas pela história. (CARNEIRO DA CUNHA, 1992, p. 12).

\section{INTRODUÇÃO}

O estudo acerca de qualquer temática a respeito dos povos indígenas impõe a necessária compreensão dos processos históricos de um determinado contexto cultural ou étnico, no qual se insere o recorte delimitado do fenômeno a ser pesquisado. Contudo, a exclusão dos indígenas na e da História do Brasil e o desconhecimento de suas histórias se constituem, ainda hoje, em algumas das problemáticas centrais nas produções, pesquisas e estudos a respeito dos povos originários.

De acordo com Melatti (1994), pouco se sabe sobre os processos históricos das sociedades nativas ${ }^{3}$, tanto no que diz respeito à origem como nos últimos cinco séculos de contato com a sociedade não indígena. Nessa perspectiva, Carneiro da Cunha (1992, p. 11) enfatiza que:

[...] hoje ainda, por Ihes desconhecermos a história, por ouvirmos falar, sem entender-Ihe o sentido ou o alcance, em sociedades "frias", sem história, porque há um tropo propriamente antropológico que é o chamado "presente etnográfico", e porque nos agrada a ilusão de sociedades virgens, somos tentados a pensar que as sociedades indígenas de agora são a imagem do que foi o Brasil pré-cabralino [...].

Nesse sentido, refletir sobre os sujeitos contemporâneos não é tarefa fácil, sobretudo daqueles que foram relegados ao passado, subalternizados, invisibilizados e "Excluídos da História"4. E, ao negar a História aos e dos povos indígenas, reduzidos pelas áreas do conhecimento das sociedades ocidentais ao mundo da natureza, recusou-se não somente sua capacidade de reflexão, mas, nomeadamente, postulou-se a impossibilidade de humanidade desses sujeitos.

\footnotetext{
${ }^{3}$ O autor aponta que até 1967 , embora houvesse mais de duas mil obras publicadas a respeito de diversas etnias indígenas, poucos conheciam sua história (MELATTI, 1994).

${ }^{4}$ Título da obra da historiadora francesa Michelle Perrot. No livro Os excluídos da história (1988) a autora aborda a supressão dos "operários, mulheres e prisioneiros" europeus da reflexão da área da História. O não reconhecimento da condição de sujeitos históricos pelo pensamento eurocêntrico não ocorreu somente com grupos sociais, étnicos e de gênero das sociedades colonizadas, mas também nos países colonizadores.
} 
Nessa acepção, é necessário conduzir nossas indagações a respeito da postura dos saberes acadêmicos, bem como da sociedade civil brasileira e do poder público, que insistem em não reconhecer os indígenas como sujeitos históricos, isto é, como seres humanos capazes cognitivamente de pensar, refletir e protagonizar suas histórias, de lutar por direitos e de "falar por si próprios".

A história oficial escrita pelos colonizadores, externos e internos do Estadonação, enquadrou as sociedades indígenas em um passado distante, "pré-histórico". Para além, a historiografia oficial silenciou, negou práticas culturais e a participação dos indígenas na formação da cultura brasileira. E esses povos foram descritos, pelo conjunto de saberes científicos, eurocêntricos e eurocentrados, como "primitivos", "hostis" "bárbaros", "empecilho", "selvagens", "preguiçosos" e todos os demais termos que constam, ainda hoje, nos manuais escolares, denominados de livros didáticos ${ }^{5}$; além de se perpetuarem também no imaginário coletivo da maioria dos grupos sociais que compõem a sociedade brasileira.

Tais representações negativas, construídas pela historiografia, conformou a ideia comumente aceita de que a História Indígena se contrapõe ou é diferente da História Nacional. Nesse sentido, faz-se necessário apontar que o conhecimento da História dos povos originários é necessário, inclusive, para a compreensão dos processos históricos dos contextos regionais nos quais se inserem. Visto que, conforme aponta Almeida (2007, p. 04), "[...] desde a chegada dos europeus às Américas, as histórias dos índios passaram a se entrelaçar com as dos colonizadores e não devem ser vistas de forma distinta, nem em oposição a elas".

Nessa diretriz, o cerne deste trabalho busca chamar a atenção para a necessidade do diálogo entre História e Antropologia na apreensão e discussão da história e das questões indígenas em geral. E, segundo Schwarcz (2005, p. 119), "Não é de hoje que se debatem as relações entre história e antropologia", assim, não é objetivo aqui refletir a respeito dessas correlações; mas apontar que, como é de conhecimento, para se aproximar, no sentido de conhecer, da cultura de uma etnia indígena, é necessário compreender sua história.

E a abordagem antropológica, fundamentalmente, deve também partir da história do contexto cultural da temática proposta para o desenvolvimento

\footnotetext{
${ }^{5}$ Para uma leitura sobre as representações dos indígenas nos manuais didáticos, dentre outros, ver: Grupioni (2004, p. 481-526).
} 
de pesquisas, o que exige o diálogo "inter-pares", conforme enfatiza Cardoso de Oliveira (1998). Ao discutir conflitos entre partidários de corpus teóricos e entre as ciências sociais, o autor enfatiza que, em razão da complexidade do desenvolvimento de pesquisa, é indispensável "incentivar esse diálogo", assim como "[...] amadurecê-lo, de modo a escoimá-lo de posturas rígidas e dogmáticas" (CARDOSO DE OLIVEIRA, 1998, p. 93).

Desse modo, o diálogo entre Antropologia e História, mais que justificar, se faz necessário, pois a maioria das produções acadêmicas sobre temáticas acerca dos povos originários, tais como tradições culturais, rituais, arte, demarcação de terra, saúde, educação, protagonismo e movimentos sociais indígenas, dentre outras, foi produzida por antropólogos. Assim, quaisquer que sejam as temáticas abordadas, conforme apontado, é necessário compreender os processos históricos dos sujeitos da pesquisa. No entanto, essa se constitui numa problemática para as duas áreas do saber na medida em que, conforme chamam a atenção Melatti (1994), Carneiro da Cunha (1992) e Monteiro (1999, p. 248), "ainda sabemos pouco sobre a história desses povos".

\section{APONTAMENTOS SOBRE HISTÓRIA INDÍGENA E HISTÓRIA NACIONAL}

A oposição dos historiadores ao enfoque e pesquisa sobre as questões indígenas, segundo Monteiro (2001), é devido a ideia comum de que tal temática pertence a reflexão antropológica. Para o autor, a ausência quase que "[...] total de fontes textuais e iconográficas produzidas por escritores e artistas índios por si só impõe uma séria restrição aos historiadores" (MONTEIRO, 2001, p. 2). Compreende-se tal posicionamento ao verificar a exiguidade de trabalhos sobre os povos originários na maioria das produções historiográficas. Nota-se, de forma sutil, sua presença, como elemento simbólico, somente no processo de formação do Estado-nação brasileiro ${ }^{6}$.

\footnotetext{
${ }^{6}$ Período histórico da produção literária denominada de indianismo. E, segundo Cândido (1993), este foi um movimento estético literário, do final do século XIX, que teve como principais representantes, dentre outros, José de Alencar e Gonçalves Dias. Os autores buscavam expressar a nacionalidade brasileira, para tanto, enfatizavam a diversidade histórica cultural e populacional do país. Contudo o negro não poderia constituir-se como representante nacional, uma vez que continuava escravizado. Nesse contexto, o "índio" foi representado como "herói nacional", pois, hipoteticamente, eram livres.
} 
No contexto dos processos de construção das nações, nation-building, após as independências formais dos países das Américas, no final do século XIX e começo do XX, os intelectuais, os jornalistas, os literatos e os cientistas tinham como principal preocupação a construção das identidades nacionais. Assim, a literatura e a reflexão científica explicavam as diferenças regionais, no interior dos países, vinculando-as ao legado europeu ou às culturas dos povos nativos.

A imaginação literária, artística e jornalística transformou o "índio" em um dos elementos significativos da nação, no verdadeiro representante nacional, inclusive podia-se afirmar que eram os "nativos da terra invadida". Nesse aspecto, a produção literária produziu um discurso que disseminou a idealização e a exaltação dos indígenas, enquanto as ciências positivistas e as teorias evolucionistas, nas últimas décadas do século XIX até o início do XX, postularam a convicção na superioridade da civilização ocidental cristã e na inferioridade do "primitivismo" das sociedades originárias.

[...] essa época de triunfo do evolucionismo, prosperou a ideia de que certas sociedades teriam ficado na estaca zero da evolução, e que eram portanto algo como fósseis vivos que testemunhavam o passado das sociedades ocidentais. Foi quando as sociedades sem Estado se tornaram, na teoria ocidental, sociedades "primitivas", condenadas a uma eterna infância. E, porque tinham assim parado no tempo, não cabia procurar-lhes a história. Como dizia Varnhagen, "de tais povos na infância não há história: há só etnografia" (CARNEIRO DA CUNHA, 1992, p. 11).

Nessa perspectiva, não havia razões para os cientistas e intelectuais se ocuparem com os povos nativos, já que, de acordo com Varnhagen ${ }^{7}$, dos indígenas havia somente a possibilidade de desenvolver etnografia, e, para Karl von Martius ${ }^{8}$, em breve "deixariam de existir" (VARNHAGEN, 1980; MARTIUS, 1982, apud MONTEIRO, 2001, p. 03). No contexto histórico dos mesmos e das ideias

\footnotetext{
7 Francisco Adolfo Varnhagen (1816-1878) ficou conhecido como o Heródoto, fundador, da História no país, em seu livro, História Geral do Brasil, publicado na década de 1850. Nesta obra, os indígenas aparecem de forma secundária e são considerados seres exóticos; a propósito dos quais escreveu "com interesse, mas sem afeição" (REIS, 2006, p. 25).

${ }^{8}$ De origem alemã, naturalista e Botânico, integrou a missão científica enviada ao Brasil, em 1817, pelo governo da Áustria. Em seu discurso, de vencedor do concurso promovido pelo Instituto Geográfico Brasileiro (IHGB), publicado em 1845 pelo próprio Instituto, "afirmou que a chave para compreender a história brasileira residia "no estudo do cruzamento das três raças formadoras da nossa nacionalidade - a branca, a indígena e a negra -, esboçando a questão da mescla cultural sem contudo desenvolvê-la" (VAINFAS, 1999, p. 02).
} 
dominantes, evolucionistas e positivistas, Capistrano de Abreu (1853-1927) foi uma exceção. Pois, diferente de Varnhagem, conferiu ao indígena o papel de verdadeiros donos das terras brasileiras e afirmou que os portugueses e africanos eram os verdadeiros alienígenas e "exóticos" nessas terras (REIS, 2006, p. 98).

Vale apontar que Capistrano de Abreu foi o precursor do debate no Brasil sobre as relações possíveis entre as áreas de história e etnografia, segundo Amoroso (1996, p. 188), inclusive seu interesse "pela etnografia seguiu sempre paralelo à pesquisa histórica". E mesmo que seu ponto de vista demonstre ideias contrárias às ideologias dominantes, era um homem de seu tempo, e, desde o século XIX, a incredulidade quanto à sobrevivência dos povos indígenas estava fortemente arraigada no imaginário intelectual.

\section{HISTÓRIA E ANTROPOLOGIA: UM DIÁLOGO NECESSÁRIO}

A perspectiva de extinção dos povos nativos no país, preconizada por intelectuais, políticas indigenistas e setores políticos, marcou indelevelmente as áreas de Antropologia e História no Brasil até a década de 1970. Segundo Carneiro da Cunha (2009, p. 125), durante esse período,

[...] os índios, supunha-se, não tinham nem futuro, nem passado. Vaticinavase o fim dos últimos grupos indígenas, deplorava-se sua assimilação irreversível e a sua extinção tida por inelutável diante do capital que se expandia nas fronteiras do país. A ausência de passado, por sua vez, era corroborada por uma dupla reticência, de historiadores e de antropólogos. A reticência dos historiadores era metodológica, e as dos antropólogos, teórica.

Para a autora, os historiadores, habituados às fontes escritas, hesitavam em trabalhar com as "movediças areias da tradição oral" ou com a documentação produzida por "missionários, inquisidores, administradores, viajantes, colonos". Quanto aos antropólogos, o problema ocorria devido os partidários das diferentes correntes teóricas, como o evolucionismo, que, embora de forma "anacrônica", subsistia com seu postulado de que os indígenas não possuíam passado, "por serem, de certa forma, o próprio passado, ponto zero de sociabilidade" (CARNEIRO DA CUNHA, 2009, p. 125).

E, posteriormente, a "reticência dos antropólogos em tratar da história indígena derivava de outras ideias: as funcionalistas e as estruturalistas" (CARNEIRO 
DA CUNHA, 2009, p. 126), na medida em que, ambos corpus teóricos, por razões diversas, privilegiaram a análise sistêmica e sincrônica da sociedade. Nesse sentido, embora as questões indígenas se constituíssem, ao longo de quase todo o século XX, em objeto de atenção dos antropólogos, estes renunciavam a pesquisa histórica das sociedades nativas.

Assim, os indígenas, que conformam os sujeitos a cujo estudo a Antropologia se dedica, entre diversos fatores, por serem classificados como "ágrafos", isto é, povos sem escrita, permaneceram sem história. E os historiadores, por não possuírem instrumentos teórico-metodológicos para alcançá-los enquanto tais, não lhes conferiram a devida atenção. Desse modo, os indígenas continuaram invisíveis na área e nos estudos do campo da História e, por conseguinte, segundo Monteiro (2001, p. 04), "pouco visíveis enquanto sujeitos históricos".

Entretanto algumas mudanças significativas, conforme apontam Manuela Carneiro da Cunha (2009) e John Monteiro (2001), estes povos "surgiram" na produção historiográfica a partir dos anos de 1970. Para o autor, diante da necessidade de "reconfiguração da noção dos direitos indígenas enquanto direitos históricos", ocorreram modificações quanto às apreensões teóricas no que se refere "[...] à relação história/antropologia com demandas cada vez mais militantes de um emergente movimento indígena" (MONTEIRO, 2001, p. 5).

Nessa conjuntura, a historiografia francesa foi responsável pelo movimento que ficou conhecido como "guinada antropológica ou culturalista" (BENATTE, 2007, p. 01). Essa compreensão possibilitou estabelecer relações entre duas áreas do conhecimento vistos, até aquele período, como antagônicas: História e Antropologia. A teoria da longa duração, de acordo com análise de Le Goff (2005, p. 63), "[...] propiciou a aproximação entre a história e a aquela ciência humana que estudava sociedades "quase imóveis" - a etnologia ou, como se diz mais naturalmente hoje, antropologia".

E Fernand Braudel, em sua reflexão sobre o tempo da história, a partir da conceituação de longa duração, contribuiu com as Ciências Sociais ao apresentar a "[...] noção precisa da multiplicidade do tempo e do valor excepcional do tempo longo [...]" (BRAUDEL, 1972, p. 11). Tal teorização foi importante, já que propiciou romper com constructos fortemente enraizados na história tradicional, tais como indivíduo, acontecimento e tempo de curta duração. Do mesmo modo, foi funda- 
mental para a abordagem da nova história econômica e social, pois possibilitou a relativização da compreensão de tempo da história, e essa área do saber passou a conviver com um movimento cíclico entre temporalidades de curta, média e longa duração.

Para Braudel, os eventos históricos ocorrem na "história de fôlego" ou no tempo da longa duração, e é a partir dessa compreensão que a história precisa ser escrita, ou seja, é necessário ser coerente com sua própria lógica. A História, por ser compreendida como disciplina do 'evento', amedrontou as Ciências Sociais. Estas, por sua vez, conforme o autor, se mantiveram presas às 'estruturas'. Para o autor, os cientistas sociais

[...] entendem por estrutura uma organização, uma coerência, relações suficientemente fixas entre realidades e massas sociais. Para nós, historiadores, uma estrutura é, indubitavelmente, um agrupamento, uma arquitetura; mais ainda, uma realidade que o tempo demora imenso a despertar e a transformar (BRAUDEL, 1972, p. 21).

Desse modo, as estruturas não são fixas, suas transformações ocorrem de forma lenta, logo, demora-se a percebê-las. Assim, há um avanço na concepção de estrutura analisada pelo autor em comparação à noção de estrutura das Ciências Sociais. Sobretudo, no que diz respeito à reflexão da Antropologia estrutural, fundamentada na produção de Fernand de Saussure e na antinomia "entre história e estrutura", postulada nos trabalhos do antropólogo Radcliffe-Brown, segundo Sahlins (2003, p. 180), no período do "apogeu do funcionalismo".

O estruturalismo, corrente teórica que também atingiu a Antropologia, principalmente com as análises de Claude Lévi-Strauss em Estruturas Elementares do Parentesco, publicado em 1949, e Antropologia Estrutural de 1958, suscitou uma série de debates sobre os usos e a importância do termo 'estrutura'. Nesse contexto, ao discutir a polêmica em torno da "validade da história", Pomian (2005, p. 130) ressalta que:

O capítulo da "Antropologia estrutural", consagrado a essa última questão, equivale, de fato, a recusar à história o direito de se autodefinir enquanto ciência social. Em sua resposta, "História e Ciências Sociais. A longa duração", Fernand Braudel mostra que a história, longe de encerrar-se no estudo dos acontecimentos, não apenas é capaz de individuar as estruturas, como deve se interessar em primeiro lugar por essa tarefa. (Destaques do autor). 
Assim como a noção de estrutura de Braudel representa um marco inicial para o diálogo entre História e Antropologia, as reflexões de Marshall Sahlins (2008) também contribuem para pensar tal temática. O antropólogo norte-americano, ao apresentar a proposição de que numa relação dialética, "a estrutura se transforma pela mediação da história" (SAHLINS, 2008, p. 12), faz referências explícitas à conceituação de Braudel a respeito das "estruturas de longa duração" (SAHLINS, 2008, p. 13).

Ao analisar as oposições duais presentes na antropologia estrutural, tais como sincronia versus diacronia; estabilidade versus mudança; evento versus estrutura, dentre outras, Sahlins (2003) destaca que tais binarismos resultam do estruturalismo, inspirado na produção linguística de Ferdinand de Saussure. Este foi adotado pela reflexão antropológica sem a realização de uma reflexão mais crítica sobre suas limitações. Nessa perspectiva, o autor, ao criticar a concepção de oposição binária das estruturas, destaca:

A prática, obviamente, já foi além das diferenças teóricas que supostamente separam a antropologia e a história. Os antropólogos elevam-se da estrutura abstrata para a explicação do evento concreto. Historiadores desvalorizam o evento único em favor das recorrentes estruturas subjacentes. E também paradoxalmente, os antropólogos têm sido tão diacrônicos em pontos de vista quanto os historiadores têm sido sincrônicos (SAHLINS, 2003, p. 93).

Enfatiza-se, a partir dessas reflexões, que desenvolver pesquisas ou trabalhos sobre as questões indígenas resulta em atividades impossíveis de serem realizadas sem o diálogo entre as áreas de História e da Antropologia. E, consequentemente, os estudos de história a respeito dos povos originários ganham fecundidade através do diálogo ou da contribuição epistemológica das Ciências Sociais; do mesmo modo, nos trabalhos de Antropologia, são de fundamental importância os subsídios teóricos-conceituais de áreas do campo da História e da conceituação de tempo histórico desenvolvida por Ferdinand Braudel.

Uma vez que, a partir das contribuições desses constructos teóricos, tornou-se possível abordar e relacionar disciplinas como a História e as Ciências Sociais. Assim, na realização de estudos na área de História, buscar o diálogo com as produções da reflexão antropológica que discutem sobre temas como história e culturas indígenas, ou vice-versa, se constitui na possibilidade de aproximação do fenômeno em sua complexidade e multiplicidade. 
Com essa reflexão, mais que geral, esquemática, a respeito da noção de estrutura, buscou-se ressaltar dois aspectos relevantes na prática da investigação de temáticas relacionadas aos povos originários: primeiro, a necessidade do diálogo entre Ciências Sociais e História e as contribuições teóricas e metodológicas de ambas as áreas do saber; segundo, a fecundidade do conceito de longa duração para a reflexão sobre a presença indígena na história do Brasil.

No que tange às relações entre Ciências Sociais e História, evidenciadas no processo de mudanças epistemológicas geradas a partir da década de 1970, mediante embates teóricos travados no campo da História Nova e Escola dos Annales, salienta-se a aproximação entre áreas do conhecimento que, até aquele momento, se mantinham declaradamente como opostas, a exemplo da Antropologia e a História. Essa conduta colaborou para o surgimento dos denominados estudos híbridos e/ou estudos interdisciplinares. Em outro aspecto, refletiu também no aumento, a partir de 1990, de publicações e produções sobre a história indígena no Brasil a partir da orientação metodológica denominada de etno-história9 .

Finalmente, quanto à importância do conceito de longa duração para o desenvolvimento de pesquisas e estudos sobre os povos originários no Brasil, ressalta-se que os indígenas são sujeitos históricos atuantes e participativos, conforme demonstra a persistência na luta pela sobrevivência dos povos nativos desde o século XVI, quando teve início o processo colonizador. Em síntese, as várias formas de resistência às práticas violentadoras do invasor, tais como, enfrentamentos, revolta e fuga para não serem exterminados, escravizados e submetidos a trabalhos forçados.

Contemporaneamente, a presença de mais de trezentos povos em território nacional elucida a sobrevivência e a continuidade cultural das etnias indígenas; além de atestar a resistência, ressignificação e oposição à opressão e à violência da sociedade não indígena, incluindo-se como sujeitos participantes e ativos nos processos históricos - conforme revela, por exemplo, o protagonismo indígena

\footnotetext{
${ }^{9}$ As produções definidas como "história indígena" e "etno-história", na maioria das pesquisas que tratam de questões indígenas a partir da reflexão da área de História, é alvo de diversas polêmicas. Os autores questionam a imprecisão do uso de tais termos e da própria definição de etno-história, contudo, não é o interesse aqui aprofundar a discussão sobre tais polêmicas. Para uma leitura, ver: Galdames (1988).
} 
no Brasil durante os últimos quarenta anos. Nesse sentido, Carneiro da Cunha (2009, p. 126) ressalta que os povos nativos

[...] têm futuro: e portanto têm passado. Ou seja, o interesse pelo passado dos povos indígenas, hoje não é indissociável da percepção de que eles serão parte do nosso futuro. A sua presença crescente na arena política nacional e internacional, sua também crescente utilização dos mecanismos jurídicos na defesa de seus direitos torna a história indígena importante politicamente. Os direitos dos índios à sua terra, diz a Constituição, são históricos, e a história adquire uma imediata utilidade quando se trata de provar a ocupação. Mas ela tem também um caráter de resgate da dignidade que não se pode esquecer.

Nessa perspectiva, o resgate da história dos povos indígenas contribui para a compreensão de processos funestos promovidos pela versão da historiografia oficial, de tradição fincada no pensamento ocidental eurocêntrico, permeada por representações negativas dos indígenas, pois as formas de resistência e luta dos povos originários contra a escravidão foram descritas pelo discurso historiográfico como "indolência", "preguiça", "selvageria", "violência"10.

Do mesmo modo, o discurso da historiografia oficial suprimiu o massacre que foi a escravidão, o extermínio de etnias indígenas, a destruição de culturas, de organizações sociais e saberes tradicionais que os povos originários, do Brasil e das Américas em geral, sofreram com a invasão europeia no contexto da colonização do chamado 'Novo Mundo'. Raros são os trabalhos que tomam a escravidão indígena no Brasil como objeto de pesquisa e, até hoje, esse capítulo da história do país não consta nos livros didáticos.

Entretanto, os indígenas foram subjugados pela ação colonizadora ao longo do processo de invasão do Brasil, desde o século XVI, e a Coroa Portuguesa e os colonos construíram um conjunto de representações e produções discursivas, em nome da "civilização" e da conversão à fé cristã, que buscavam dissimular as reações dos povos indígenas quanto à invasão de seus territórios, alteração de seus modos de vida e escravidão. A historiografia oficial, bem como as políticas e a legislação indigenistas, através de constructos ideológicos e produções discursivas,

\footnotetext{
${ }_{10}$ Para uma discussão a respeito das "ideias equivocadas", ideologias justificadoras de genocídio e etnocídio dos povos indígenas, que perduram até hoje, ver: Perrone-Moisés (1992, p. 115-32); Bessa Freire (2000, p. 17-33).
} 
inverteram os papéis em relação àqueles que de fato invadiam, exterminavam, saqueavam e violentavam.

A consolidação da colonização das Américas ocorreu a partir do genocídio da população nativa. Subordinados à organização social do invasor, os que sobreviveram foram catequizados e obrigados a falar a língua do colonizador, processo que objetivava o etnocídio, isto é, o extermínio de culturas, conforme análise de Clastres (2004). Contudo, as políticas que promoveram o etnocídio e os genocídios não se findaram nos primeiros séculos de invasão do continente, na medida em que esses processos ocorrem desde aquele período e ainda não acabaram ${ }^{11}$.

Quijano (2005, p. 230), ao discutir o genocídio que ocorreu no primeiro século de colonização do continente americano, enfatiza que o extermínio de indígenas não foi "causado principalmente por la violencia de la conquista, ni por las enfermedades que los conquistadores portaban, sino porque tales índios fueron usados como mano de obra desechable, forzados a trabajar hasta morir [...]". Em relação ao extermínio de povos originários no Brasil, Carneiro da Cunha (1992, p. 13), ao apontar fatores sociais e ecológicos, tais como, densidade populacional e clima, ressalta que:

[...] nefasta foi a política de concentração da população praticada por missionários e pelos órgãos oficiais [...]. O exacerbamento da guerra indígena provocada pela sede de escravos, as guerras de conquista e de apresamento em que os índios de aldeia eram alistados contra os índios ditos hostis, as grandes fomes que tradicionalmente acompanhavam as guerras, a desestruturação social, a fuga para novas regiões das quais se desconheciam os recursos ou se tinha de enfrentar os habitantes, a exploração do trabalho indígena, tudo isso pesou decisivamente na dizimação dos índios.

Todavia, diversos povos indígenas resistiram a tais processos, sobreviveram, preservaram línguas e ressignificaram tradições e diversos elementos culturais, o que revela o movimento dos indígenas na história, que começou antes mesmo

\footnotetext{
${ }^{11}$ Os Relatórios sobre Violência contra os Povos Indígenas no Brasil, publicados anualmente pelo Conselho Indigenista Missionário (CIMI), apresentam dados e informações sistematizadas que são coletadas junto aos órgãos públicos e notícias veiculadas pela imprensa. Os Relatórios são divididos em quatro partes: "Crimes contra o patrimônio"; "Violência contra a pessoa praticada por particulares e agentes do poder público"; "Violências provocadas por omissão do poder público"; e, por último, "Violência contra Povos Indígenas Isolados" (CONSELHO INDIGENISTA MISSIONÁRIO [CIMI], 2015).
} 
da invasão dessas paragens pelos portugueses. E, como é conhecido, não existem certezas quanto à forma e ao período em que os povos nativos chegaram aqui, há somente hipóteses e teorias. E eram milhares de indígenas quando se deu início ao processo de colonização e, atualmente, os mais de 300 povos "indígenas somam, segundo o Censo IBGE 2010, 896.917 pessoas. Destes, 324.834 vivem em cidades e 572.083 em áreas rurais, o que corresponde aproximadamente a 0,47\% da população total do país" (INSTITUTO SOCIOAMBIENTAL, s.d.) ${ }^{12}$.

\section{O MOVIMENTO DOS INDÍGENAS NA HISTÓRIA: OS AKWẼ-XERENTE}

Os dados demográficos demonstram que esses povos sobreviveram, possuem história e são aptos a contá-la no presente, inclusive, sob o ponto de vista deles. E é possível apontar um conjunto de temas que demonstram o movimento dos indígenas no tempo histórico, tais como, as bandeiras e o processo de ocupação do interior do país; guerras e alianças entre índios e europeus; culturas indígenas; e, no período mais recente, a partir da década de 1970, o protagonismo e avanço dos movimentos sociais indígenas.

Entretanto, opta-se aqui pela descrição e leitura histórica no tempo da longa duração, conforme análise de Braudel, da história do contato interétnico de um povo indígena, no contexto das políticas e legislação indigenistas, ao longo dos últimos 250 anos. A história dos Akwẽ-Xerente, a partir do conceito de longa duração, nos permite captar aspectos fundamentais para repensar o lugar do indígena na história e na historiografia, compreender a forma como os indígenas foram representados na história brasileira, além de explicitar a supressão de um dos capítulos mais trágicos da história do país, a escravidão dos povos originários.

E, ao partir da história de lutas e resistência à opressão - que não são simples atos de "selvageria", assim considerados, historicamente, por parte dos invasores portugueses, ao longo do Império e, mais recente, do Estado republicano-, busca-se mostrar que os povos indígenas são protagonistas de suas histórias. Nesse

\footnotetext{
12 Não há consenso quanto a densidade populacional indígena no Brasil de hoje, em razão dos métodos adotados de coleta de dados por diferentes instituições que trabalham com as populações indígenas, tais como: Fundação Nacional do Índio (FUNAI), Secretaria Especial de Saúde Indígena (SESAI). Dessa forma, sugere-se aqui a leitura das análises de: Santilli (2000); Melatti (2004); e Luciano Baniwa (2006).
} 
sentido, o povo Akwẽ resistiu e lutou por seu território, desenvolveu dinâmicas, formas e meios de preservarem suas tradições culturais, no contexto do contato violentador com os colonizadores externos e internos à nação, bem como com parcelas da sociedade nacional.

Seu dialeto é o Akwẽ, utilizado na vida cotidiana entre os indígenas nas aldeias e no ensino das crianças, enquanto que o uso da língua portuguesa ocorre somente na relação com os não indígenas. Os Akwẽ, segundo Wãkainẽ (2012, p. 83), "significa gente", mas foram denominados pelos não indígenas de Xerente, pertencem ao tronco linguístico Macro-Jê. E, de acordo com Nolasco (2010), junto com os Xavantes do Mato Grosso, que se autodenominam Áuwẽ, e com os Xacriabá de Minas Gerais, compõem os povos Jê central.

Segundo Nolasco, as etnias de família linguística Jê estão classificadas em Setentrionais: "os Kayapó, os Timbira, os Suyá, os Kren-akarore; como Centrais: os Akwẽ-Xerente, os Xavante e os Xakriabá; e como Meridionais: os Kaingang e os Xokleng" (NOLASCO, 2010, p. 29). Atualmente, o estado do Tocantins possui uma população indígena estimada em 13.800 indivíduos (BRASIL, 2013), divididos, segundo a língua, em oito povos: Inỹ (Karajá; Xambioá; Javaé), Akwẽ (Xerente), Timbira (Krahô, que se autodenominam Meri; Apinajé ou Panhi; Krahô-Kanela) e Avá (Canoeiro).

Os Akwẽ-Xerente, habitantes do Cerrado, Homo cerratensis (BERTRAN, 2000), há alguns séculos ocupam a bacia do Rio Tocantins. Vivem na região tradicionalmente ocupada pela etnia, próximo ao município de Tocantínia, TO. Este se sobrepõe territorialmente às Terras Indígenas Xerente, segundo Nolasco (2010), demarcada em 1972 com 167.542 hectares; e a Terra Funil, demarcada em 1988, com 15.703 hectares (juntas somam o total de 183.245,902 hectares). Esse território localiza-se a, aproximadamente, $70 \mathrm{~km}$ da capital do estado do Tocantins, Palmas.

A população atual Xerente, em torno de 4.000 indígenas, encontra-se distribuída em 77 aldeias (BRASIL, 2017), divididas em cinco regiões: Funil, Porteira, Bupré, Rio Sono e Brejo Cumprido. E há os que residem em Tocantínia, o município com maior população indígena do estado do Tocantins, e um dos maiores do país. O número de habitantes do município em 2016, de acordo com os dados do Instituto Brasileiro de Geografia e Estatística (INSTITUTO BRASILEIRO DE 
GEOBRAFIA E ESTATÍSTICA [IBGE], 2016), é de apenas 7.387². Desse total, 3.739 (BRASIL, 2017) são indígenas, dos quais, 3.382 vivem nas aldeias, zona rural, e 357 são denominados de "desaldeados", ou seja, residem na cidade.

A situação de contato ou as relações interétnicas na cidade, entre o povo Akwẽ-Xerente e a população não indígena, são singulares. A localização do território indígena Xerente próximo do município, cerca de 18 km, entre os Rios Tocantins e do Sono, gera relações cotidianas e, historicamente, conflituosas com os não indígenas.

Conforme os documentos oficiais do século XVIII, os primeiros contatos entre os Xerente e parcelas da sociedade nacional ocorreram com as tentativas dos colonos de escravização e a imposição dos aldeamentos. Nesse contexto, em 1851, surgiu Piabanhas ou Aldeamento Teresa Cristina, atual Tocantínia, TO, após a fuga/resistência dos Aldeamentos Carretão ou Pedro III e do Aldeamento Graciosa.

É válido apontar que pouco se sabe sobre a história dos Akwẽ-Xerente nos três primeiros séculos de colonização portuguesa no Brasil. E, entre as hipóteses acerca da razão de dispersão inicial de alguns povos do grupo Macro-Jê, que atualmente habitam o Brasil central, a de que teriam vindo do litoral brasileiro é a mais aceita. O antropólogo Curt Nimuendajú (1942), que viveu entre os Xerente na década de 1930, quando registrou relatos dos mitos e da memória coletiva do grupo, aponta que os Akwẽ viveram em uma região de seca do Nordeste brasileiro:

[...] region where droughts formed a constant and terrifying menace for man. That the Sere'nte once lived in such a zone is indicated by a passage in a version of the Asare' Myth [...] Further, the Sere'nte themselves say that they formerly dwelt farther east toward the Rio São Francisco" (NIMUENDAJÚ, 1942, p. 94).

A partir dessa hipótese, depreende-se que os Akwẽ-Xerente viviam no litoral nordestino e, depois, migraram para o cerrado semiárido contíguo ao Rio Tocantins, local onde habitam até o presente. A partir do século XVIII, o contato interétnico do povo Akwẽ com parcelas da sociedade nacional, de forma sistemática, é marcado pela violência, conflito e resistência à escravidão, conforme

\footnotetext{
${ }^{13}$ Estimativas do IBGE (2016) apontam para um aumento da população do ano de 2010 de 6.736 para 7.387 em 2016.
} 
explicitado, com a implantação dos primeiros aldeamentos na Capitania de Goiás, mediante política e legislação indigenista imposta pela Coroa Portuguesa.

A política de aldeamento no Brasil, segundo Beatriz Perrone-Moisés (1992, p. 118), alicerçada no princípio de cristianização dos indígenas, através da "catequização", intentava transformá-los em "civilizados", isto é, em "vassalos úteis", de acordo com os "documentos do século XVIII". Quanto ao século XIX, Carneiro da Cunha (1992, p. 144), ao analisar as políticas indigenistas daquele período, ressalta que a ideia de civilização, agregada à de catequização, significava submeter os indígenas às leis e os obrigar ao trabalho, ou seja, à escravidão.

E, embora a legislação fosse contrária ao trabalho escravo dos povos originários, contraditoriamente se constituiu em um conjunto de artifícios para exercer controle e propriedade sobre os indígenas. Contudo, juridicamente, não se caracterizava como escravidão, tal como expresso, durante os primeiros séculos de colonização, nas Leis adaptadas das Ordenações Manuelinas e Filipinas; no documento de 1549, conhecido como Regimento Tomé de Souza; e nas declarações de guerras contra os indígenas, denominadas de "Guerras Justas"14.

Desse modo, os indígenas eram apresados, obrigados a viverem nas aldeias implantadas pelos colonizadores, forçados a trabalhar para suprirem as necessidades de toda a população dos aldeamentos, dos próprios indígenas, mas também, dos missionários, colonos, expedições da Coroa, bandeirantes, mineradores e dos produtores agrícolas. É neste sentido que as políticas e legislação indigenistas devem ser compreendidas, ou seja, a partir das tentativas de imposição do trabalho forçado pelo invasor aos povos originários.

A catequese e a civilização são os princípios centrais de todo esse projeto, reafirmados ao longo de toda a colonização: justificam o próprio aldeamento, a localização das aldeias, as regras de repartição da mão de obra aldeada, tanto a administração jesuítica quanto a secular, escravização e o uso da força em alguns casos. Todo o projeto baseia-se na crença de que o que se oferece aos indígenas realmente representa um bem para eles. No século XVIII, o valor máximo, que, até então, era a salvação da alma, será substituído pela ideia de felicidade inerente à vida civilizada e sujeita a leis positivas. De qualquer modo, trata-se de trazer os índios àquilo que é considerado, pelos europeus, como um bem maior (PERRONE-MOISÉS, 1992, p. 122).

14 “[...] A guerra justa, instituição que data das Cruzadas, é usada do século XVI ao início do XVIII no Brasil para dar fundamento à escravização de índios livres" (CARNEIRO DA CUNHA, 1992, p. 142). 
A construção contínua de aldeamentos na Província de Goiás, de acordo com Marlene Castro Ossami de Moura (2006), ao analisar o processo de etnogênese dos Tapuios do Carretão, se estendeu por mais de cem anos e pode ser dividida em duas fases: a primeira, foi devido a sacra auri fames e o surgimento de vários povoados. E o segundo período teve início a partir de "[...] 1755, quando a mineração entrava em fase de decadência. Esta agravou-se a partir de 1780, quando já se consolidava um novo ciclo econômico na província de Goiás, baseado na agropecuária" (OSSAMI DE MOURA, 2006, p. 29).

Assim, o intervalo entre a primeira e a segunda etapa de construção dos aldeamentos e presídios ${ }^{15}$ corresponde ao enfraquecimento da mineração em Goiás e à transição para a atividade agropastoril. Nesse contexto, a quantidade de arraiais, povoados, vilas e vilarejos diminuiu e ocorreu um aumento significativo de ocupação das áreas rurais com o objetivo de desenvolver novas atividades agropastoris. Tais processos acirraram conflitos e ameaças aos povos indígenas.

Nessa fase de decadência da produção aurífera em Goiás, em 1788, foi criado o Aldeamento Pedro III ou Carretão ${ }^{16}$. Desativado no final do século XIX, foi formado inicialmente para aldear os Xavante, contudo, distintos grupos indígenas apresados igualmente foram obrigados a se sujeitarem às condições violentadoras praticadas no Carretão, como os Akwẽ-Xerente, os Karajá, os Javaé, os Kayapós; e "[...] também negros escravos que fugiam das fazendas de seus senhores" (OSSAMI DE MOURA, 2006, p. 29).

\footnotetext{
${ }^{15}$ Os presídios ou "praças fortes com destacamento militares", construídos de forma recorrente, conforme Carneiro da Cunha (1992), a partir da segunda metade do século XIX, em várias províncias no Brasil, se tornaram instrumentos efetivos no apresamento e envio de indígenas para os aldeamentos. Em Goiás, ao longo dos rios Tocantins e Araguaia, esses locais foram "[...] ladeados de aldeias com seus missionários" (CARNEIRO DA CUNHA, 1992, p. 141).

${ }^{16}$ Segundo Moura (2006, p. 29), a "Área Indígena Carretão, também conhecida regionalmente como "Fazenda dos Tapuios", situada entre a Serra Dourada (ou do Tombador) e o rio São Patrício (ou Carretão), nos municípios de Rubiataba e Nova América". Quanto ao nome do aldeamento, em uma nota, a autora esclarece que: "Carretão é o nome do rio em cuja margem foi construído o aldeamento. Na sua cabeceira, ele recebe o nome de Taboão; no local da área indígena atual, Carretão; depois, até a sua embocadura com o rio das Almas, São Patrício. Para Frei Gil de Vilanova Gallais [...], Carretão era o nome de um grande veículo de madeira, que servia para transportar índios escravos acorrentados para Vila Boa. Já a denominação Pedro III foi uma homenagem ao tio e esposo da rainha de Portugal, Maria I: o rei Dom Pedro III. Alguns autores juntam os dois nomes: Aldeamento Pedro III do Carretão" (OSSAMI DE MOURA, 2006, p. 46).
} 
O Aldeamento Carretão agrupou diferentes etnias indígenas, escravos de origem africana, que fugiam das fazendas, e a população não indígena constituída por funcionários do governo, famílias de colonos etc. Assim, o aldeamento tinha como objetivo homogeneizar as etnias indígenas, impor a língua portuguesa e desarticular as organizações socioculturais ao promover a miscigenação interétnica entre os Akwẽ-Xerente, os Xavante, os Karajá, os Kayapó, entre outros, através de um sistema de produção e exploração similar ou igual à escravidão.

Desse modo, nos primeiros séculos de invasão do Brasil, os aldeamentos se constituíram em uma política indigenista utilizada pelos colonizadores, conforme explicitado, para legitimar o trabalho escravo e servil, bem como, para impor o relacionamento interétnico, inexistente até então entre os povos indígenas, com o intuito de se apropriarem de suas terras.

O Carretão, formado durante a vigência da política indigenista pombalina, tinha como diretrizes a integração do indígena à sociedade nacional, ocupação dos territórios e a transformação destes em mão de obra para a produção agrícola. Entretanto, os aldeamentos tiveram curta duração, o que ocorreu, é consensual entre os autores que discutem a temática, foi devido aos maus tratos sofridos pelos indígenas, às doenças transmitidas, à imposição de trabalho escravo pelos colonos, que os levaram à morte ou à fuga/resistência.

Nesse sentido, de acordo com Darcy Ribeiro (1996, p. 80), “[...] experienciar a vida civilizada", na realidade, um conjunto de violência praticadas pelos não indígenas, não teria lhes agradado, pois, logo "[...] começaram a escapar rumo ao norte, para o antigo território tribal". Após o Carretão, os Xerente tiveram, como experiência de contato sistemático com os não indígenas, o Aldeamento Graciosa. Criado, em 1824, para aldear exclusivamente a etnia, foi implantado às margens do ribeirão Taquaruçu, na confluência com o Rio Tocantins.

O Aldeamento Graciosa, construído durante o Império, fase em que a produção econômica em Goiás encontrava-se voltada para a agropecuária e o comércio fluvial, visava fornecer mão de obra para o comércio e a navegação:

Como a ligação terrestre entre a região litorânea e a província de Goiás era difícil, os rios Araguaia e Tocantins se apresentavam como possíveis soluções para o desenvolvimento do transporte e do comércio da região. No entanto, a navegação tinha como desafio a presença de várias nações indígenas ainda 
não pacificadas e hostis habitando o curso dos dois rios. Para enfrentá-las, o governo da província de Goiás optou por construir, ao longo do curso de ambos os rios, aldeamentos indígenas e presídios destinados a fornecer apoio e segurança às embarcações e às regiões circunvizinhas. (OLIVEIRA E SILVA, 2013, p. 69).

Implantado pelo governador da Capitania de Goiás, Raymundo José da Cunha Matos, que o batizou com o nome de Graciosa em homenagem à sua filha, o Aldeamento foi construído após a imposição de um acordo que infligia aos Akwẽ-Xerente:

Primeiro - Que os Xerente se aldeassem em uma ou mais aldeias à margem esquerda do rio Taquarussú, junto à confluência deste com o rio Tocantins, no sítio denominado Barreira Vermelha, doze léguas ao norte de Porto Real; Segundo - Que os Xerente não incomodariam os habitantes dos arraiais de Monte do Carmo, Porto Real, Pontal, e demais localidades, e além disso auxiliariam os comerciantes que navegassem pelo Tocantins;

Terceiro - Os Xerente obedeceriam ao Governo da Província e serviriam de barreira contra outros índios que atacassem o aldeamento;

Quarto - Os Xerente não pagariam contribuições enquanto não estivessem estabelecidos e produzindo o suficiente para se alimentarem;

Quinto - Os chefes Xerente não fariam guerra ofensiva e não imporiam pena de morte entre si a seu arbítrio;

Sexto - Deixariam de se vender como escravos;

Sétimo - Os Xerente receberiam a religião católica (SILVA, 2006, p. 91-2).

Em conformidade com essas exigências, o Aldeamento Graciosa foi construído em uma localidade de extrema violência, região de garimpos no Rio Tocantins, a "doze léguas ao norte de Porto Real", depois Porto Imperial, atual município de Porto Nacional, e do Arraial de Pontal. Local de enfrentamentos armados entre indígenas e não indígenas, desde o século XVIII, com os conflitos gerados a partir da produção aurífera. E, em meio as diversas violências impostas pelos colonos, os Akwẽ também vivenciaram relações conflitivas com diferentes etnias indígenas.

Durante a permanência dos Akwẽ no Aldeamento Graciosa, mais precisamente no final do ano de 1824, sofreram ataques de outros povos indígenas, segundo aponta Silva (2006, p. 93), primeiro dos Noraquagés (Nhyrkwãjê) e, em seguida, pelos Xavante. Graciosa, como os demais aldeamentos em Goiás, durou pouco tempo, pois os Xerente começaram a abandonar sistematicamente o 
Aldeamento alguns anos antes de ser desativado, em 1856. E, dentre as razões para a fuga/resistência, conforme assinala o autor, destaca-se: os indígenas eram obrigados a se dedicarem à produção agrícola e à navegação, logo, eram submetidos ao sistema disciplinar de produção, moradia e religião dos colonizadores, diferente da cultura indígena; má administração do aldeamento; falta de manutenção e escassez de alimentos; etc.

É importante indicar que os documentos oficiais, sobre as tentativas de

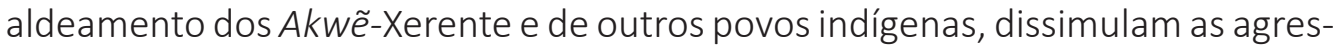
sões praticadas pelos administradores dos aldeamentos e invertem os papéis entre os envolvidos quanto à prática de diversos tipos de violência no processo de invasão dos territórios indígenas. Nesse sentido, as formas de resistência dos Akwẽ aos atos violentadores do colonizador foram denominadas de "selvagens", "hostilidades" e "maldades", por exemplo, de acordo com o documento de 1831:

Estragos feitos pelos índios Chavantes e Cherentes nas vilas e fazendas dos habitantes da província que Va Exa obre o que entender melhor afim de precaver a continuação de tais maldades, lançando mão não ao princípio dos meios brandos, a ver se possível chamá-los a nossa amizade, mas no caso de necessidade empregando então as forças para ao menos os fazer afugentar para o interior, e por termo deste modo as hostilidades que tem impunemente praticado (Correspondências diversas do Palácio do Rio de Janeiro ao Governo de Goiás, 1831, manuscrito, apud ATAíDES, 2001, p. 139).

Nesse ínterim, nas margens do Córrego Piabanha, "[...] cerca de 30 léguas de Porto Nacional e 12 léguas de Pedro Afonso", na Bacia do Rio Tocantins, de acordo com a documentação do século XIX, foi construído para aldear os Xerente o Aldeamento Teresa Cristina, nome em homenagem à Imperatriz, ou "Piabanhas, fundado em 1851 na confluência do Ribeirão d'este nome com o Tocantins com mais de 3000 índios Cherente e Chavante que se dão à agricultura e à navegação" (Correspondência da Presidência ao Ministério dos Negócios do Império, 18451848, manuscrito, apud ATAÍDES, 2001, p. 225).

Fundado pelo Frei Raphael de Taggia, inicialmente para reunir indígenas Xerente, o Aldeamento contou também com um contingente de índios Xavante e, posteriormente, com os Krahô. No Aldeamento Teresa Cristina, em 1851, havia:

[...] 3.800 entre Xerente e Xavante. Em 1874, além dos Xerente, também havia Krahô vivendo em Tereza Cristina, e a população era de 3.000 pes- 
soas. Já em 1880, as informações dão conta dos Xerente com os Xavante em Tereza Cristina. Porém, desta vez, contam com o número de 2.000. Em 1886, entretanto, são apenas 1.500 indivíduos [...]. A tutela desenvolvida pelo Estado e por religiosos para os Xerente no aldeamento de Piabanhas seguiu até o fim do Império no Brasil (SILVA, 2006, p. 99).

Desse modo, além do contato interétnico com povos indígenas, a partir de 1870 o capuchinho Frei Antônio de Ganges iniciou novo processo de catequização no Aldeamento Piabanhas, que atraiu também, segundo Darcy Ribeiro (1996, p. 60): "[...] uma população sertaneja que invadia lentamente, com seus rebanhos os campos de caça dos índios, formando-se um arraial".

E, ao resistir à invasão de suas terras, os indígenas tentaram expulsar os colonos, o que acirrou os conflitos e os levou a procurar o Imperador D. Pedro II, em busca do seu "título indiscutível ao território tribal".

Acham (os Xerente) que têm direito às terras que ocupam; quando os cristãos procuram apoderar-se delas consideram isso uma revoltante injustiça e vão logo aos extremos. Quando o Pe. Antônio Fundou Piabanhas, não tardaram a verificar-se conflitos desse gênero, com tal caráter de gravidade que necessário recorrer às autoridades superiores. A questão foi levada ao tribunal do Imperador, que se pronunciou no sentido de um acordo. Entregou aos Índios uma vasta extensão de terras, para gozo exclusivo seu, e das quais em hipótese alguma poderiam os cristãos desalojá-los. Os índios aceitaram lealmente a decisão do grande chefe do Rio, pelo qual têm o mais profundo respeito. Mas nas regiões que Ihes haviam sido reservadas havia belas pastagens, que os cristãos se sentiram muito felizes em aproveitar para os seus rebanhos. Acharam a coisa mais simples deste mundo mandar para lá o gado. Mas os índios não se mostraram de acordo e todo o gado que entrasse limites adentro do território que Ihes havia sido designado era abatido sem misericórdia. Daí as queixas e recriminações (GALLAIS, 1942, p. 139-40, apud RIBEIRO, 1996, p. 66-67).

E, desde então, o contato sempre conflitivo entre os Akwẽ e os não indígenas se intensificou ininterruptamente, marcado por experiências de desrespeito e agressões físicas e simbólicas, explícita ou implicitamente. Da mineração dos bandeirantes à pecuária com os colonizadores e, no contexto político e econômico atual do estado do Tocantins, em que o projeto desenvolvimentista e o agronegócio são prioridades para o poder público, estão vivenciando o processo de invasão de seu território pela agropecuária extensiva dos criadores de gado e latifundiários 
produtores de grãos em larga escala, além dos grandes empreendimentos de infraestrutura como a construção da hidrelétrica de Lajeado.

Assim, a história do contato dos Xerente pode ser pensada, nos últimos 250 anos, a partir da conceituação de longa duração de Braudel. Visto que, a partir dessa perspectiva, revelam-se os objetivos das políticas e legislação indigenistas, isto é, a escravidão dos povos indígenas, bem como elucida as formas e meios que essa etnia indígena encontrou para resistir e que foram descritas pela historiografia brasileira oficial como "selvageria".

A resistência, que se intercalou entre guerra e paz, marcada por conflitos, estiveram presentes nos três aldeamentos: Carretão, Graciosa e Tereza Cristina. E, em meio ao extermínio, os Akwẽ-Xerente decidiram (aceitaram), como última forma de lidar com os não indígenas, se aldearem, e, assim, sobreviverem física e culturalmente. E mesmo com o advento do processo de formação do Estado nacional brasileiro, a situação dos Xerente prosseguiu com luta e resistência.

Quanto à legislação e políticas indigenistas, a lógica era homogeneizar as etnias, ao promover a miscigenação interétnica entre os Akwẽ-Xerente, Xavante, Kayapó, Karajá e distintos povos, para submetê-los a escravidão. Posteriormente, o avanço do capitalismo gerou a necessidade de novos trabalhadores para explorar o território goiano e, nesse sentido, a política assumiu nova roupagem, a de promover a miscigenação entre indígenas e não indígenas com vistas ao trabalho na agropecuária. E, por último, a própria política de aldeamentos se tornou fundamental para legitimar a ação dos governos e negar o direito dos Akwẽ sobre suas terras e, assim, realocá-los em diferentes locais sem possibilidade de sobrevivência.

Nesse sentido, o genocídio e o etnocídio dos Akwẽ ocorreram mutuamente durante o contato com a sociedade não indígena. O genocídio de forma belicosa nos séculos iniciais da colonização; e o etnocídio a partir do XVIII, com a política de aldeamentos, que acirrou os conflitos. Este último afetou a cultura e a educação Xerente, a partir da imposição da fé cristã e do uso do português como língua oficial. Processo que objetivou gerar a perda de conhecimentos, saberes, linguagens e experiências próprias. Ou seja, a partir do conhecimento hegemônico, que se fundamenta no eurocentrismo, nesse caso, a língua do colonizador, intentava-se fazer com que negassem sua identidade e sua cultura ao adotar aquela religião. 
Entretanto, os Akwẽ-Xerente não somente sobreviveram a tais processos colonizadores e de omissão do poder público, como têm se fortalecido, cotidianamente, resgatado e lutado pela continuidade de sua cultura. E, após mais de dois séculos e meio de contato com a sociedade não indígena, muitas mudanças e ressignificações socioculturais ocorreram. E práticas culturais, língua, saberes, rituais foram mantidos e também ressignificados e, assim, a etnia resguarda sua identidade e dá continuidade à sua organização sociopolítica, a partir de uma especificidade étnica designada pela Antropologia de sociedade dualista.

Segundo De Paula (1999), os Xerente têm como fundamento o sol e a lua como criadores de tudo que existe no mundo e que, concomitantemente, formulam suas duas metades, representando a noite e o dia, bem como seus respectivos clãs. Conforme o autor, a sociedade Akwẽ:

[...] está centrada numa divisão em duas metades sócio-cosmológicas- Doí e Wahirê - associadas respectivamente ao Sol e Lua, os heróis míticos fundadores da sociedade Xerente. A onça (huku) também faz parte da mítica Xerente, já que foi responsável por ensinar-Ihes o uso do fogo. A metade Doí inclui os clãs Kuzaptedkwá ("os donos do fogo"), Kbazitdkwá ("os donos do algodão") e Kritóitdkwa ("os donos do jogo com a batata assada" ou "donos da borracha"); e a metade Wahirê, os clã Krozaké, Kreprehí e Wahirê, que tem o mesmo nome da metade. As duas metades e seus respectivos clãs possuem entre si uma rede de deveres e obrigações recíprocas. As metades, os seis clãs e as linhagens que os constituem são patrilineares, isto é, passam de pai para filho, de avô paterno para neto, ou, sobrinho-neto. Assim, cada um dos clãs Xerente possui um conjunto de nomes próprios que são passados de geração a geração, responsáveis pela identificação e distinção dos indivíduos Xerente no plano de sua organização social (DE PAULA, 1999, p. 02).

Cada clã é representado por pinturas corporais, que são utilizadas por adultos em ocasiões cerimoniais ou festivas e pelas crianças cotidianamente ${ }^{17}$. Assim, contrariando o intento dos colonizadores e, mais recentemente, segmentos da sociedade nacional e do Estado, com suas ações integracionistas, que tentaram e preconizaram o fim dos povos indígenas no Brasil; para além, ao escreverem

\footnotetext{
17 "As cores básicas da pintura corporal Xerente são confeccionadas com os seguintes elementos: carvão misturado com pau-de-leite faz o preto; sementes de urucum fazem o vermelho e o branco é completado com penugem de periquito ou algodão. Antes da pintura, os corpos são untados com óleo de babaçu. Os detalhes - círculo ou traços - são esculpidos em pedaços de miolo de tora de buriti, e utilizados como uma espécie de "carimbo"" (DE PAULA, 1999, p. 3).
} 
sua própria compreensão da história, de acordo com a autora Indígena Xerente

Sílvia Sibakadi (2012, p. 87), os Akwẽ "continuam, na prática, com seus ritos e mitos, realizando as suas festas com canções, danças, para as quais se enfeitam e pintam. Eles mantêm viva ainda uma grande parte de sua cultura. A sua alma continua profundamente indígena [...]".

Vilmar Wãkainẽ (2012) ressalta que, desde os primeiros contatos, até os dias atuais, continuam ocorrendo vários tipos de violências, preconceitos, desrespeitos e, sobretudo, a imposição de uma identidade alheia ao seu povo. Contudo, os Xerente, conforme o autor, "são o que sempre foram": um povo com suas particularidades, único no mundo. E "[...] Queremos reafirmar que nos identificamos, não como índios simplesmente, e sim como gente. Nós nos denominamos como 'gente de verdade', isto é, Akwẽ' (WÃKAINẼ, 2012, p. 82).

$E$, àqueles que negam sua condição de atores sociais e históricos capazes cognitivamente de refletir, ensinam uma importante lição, afinal, parafraseando Vilmar Wãkainẽ, é no respeito às diferenças que se consegue viver em harmonia, em um país formado por sociedades diversas. E, por isso, o respeito à cultura de cada povo indígena é importante, pois "[...] cultura é mais do que uma simples palavra, é a própria vida de um povo, a sua maneira de interpretar os acontecimentos, os fenômenos da natureza (cosmovisão) e se comunicar com divindades" (WÃKAINẼ, 2012, p. 82).

\section{REFERÊNCIAS}

ALMEIDA, Maria Regina Celestino de. Os índios na história: abordagens interdisciplinares. (Apresentação). Revista Tempo, Rio de Janeiro, n. 23, p. 11-4, jul. 2007.

AMOROSO, Marta Rosa. Capistrano de Abreu e os índios. In: REIS, Elisa; ALMEIDA, Maria Hermínia Tavares de; FRY, Peter (Org.). Política e cultura - visões do passado e perspectivas contemporâneas. São Paulo: HUCITEC-ANPOCS, 1996. p. 182-96.

ATAÍDES, Jézus Marco (Org.). Documenta Indígena do Brasil Central. Goiânia: Editora da UCG, 2001.

BENATTE, Antônio Paulo. História e Antropologia no campo da Nova História. Revista História em Reflexão, Dourados, v. 1, n. 1, p. 1-25, jan./jun. 2007.

BERTRAN, Paulo. História da terra e do homem no Planalto Central: eco-história do Distrito Federal- do indígena ao colonizador. Brasília: Verano, 2000. 
BESSA FREIRE, José Ribamar. Cinco ideias equivocadas sobre os índios. Revista do Centro de Estudos do Comportamento Humano, Manaus, n. 1, p. 17-33, set. 2000.

BRASIL. Ministério da Saúde. Secretaria Especial da Saúde Indígena. Departamento de Gestão da Saúde Indígena. Coordenação de Monitoramento e Avaliação. DSEI Tocantins. Dados gerais do Dsei Tocantins, referentes a 2013. Disponível em: <http://portalarquivos. saude.gov.br/images/pdf/2014/fevereiro/25/Dsei-Tocantins.pdf>. Acesso em: 18 fev. 2017.

- Ministério da Saúde. Secretaria Especial da Saúde Indígena. Departamento de Gestão da Saúde Indígena. Coordenação de Monitoramento e Avaliação. DSEI Tocantins. Pólo Base Indígena Tocantínia. Dados gerais da população Xerente, referentes a 2017. Tocantínia, 2017.

BRAUDEL, Fernand. História e Ciências Sociais. Lisboa: Editorial Presença, 1972.

CANDIDO, Antonio. Formação da literatura brasileira. 7. ed. Belo Horizonte: Itatiaia, 1993. v. 2.

CARDOSO DE OLIVEIRA, Roberto. O trabalho do antropólogo. Brasília: Paralelo 15; São Paulo: Editora da Unesp, 1998.

CARNEIRO DA CUNHA, Manuela. Índios no Brasil: história, direitos e cidadania. São Paulo: Claro Enigma, 2012. (Coleção Agenda Brasileira).

. Cultura com aspas. São Paulo: Cosac Naify, 2009.

- Introdução a uma História Indígena. In: CARNEIRO DA CUNHA, Manuela (Org.).

História dos índios no Brasil. São Paulo: Cia da Letras; Secretaria Municipal de Cultura; FAPESP, 1992.

CLASTRES, Pierre. Arqueologia da violência: pesquisas de antropologia política. São Paulo: Cosac Naify, 2004.

CONSELHO INDIGENISTA MISSIONÁRIO (CIMI). Relatório violência contra os povos indígenas no Brasil - dados de 2014. Brasília: CIMI, 2015.

DE PAULA, Luís Roberto. Xerente. Povos Indígenas no Brasil. Instituto Socioambiental (ISA), ago. 1999. Disponível em: <https://pib.socioambiental.org/pt/povo/xerente/1173>. Acesso em: 22 out. 2016.

GALDAMES, Osvaldo Silva. ¿Etnohistoria o historia indigena? In: GALDAMES, Osvaldo Silva; CÁRDENAS, Eduardo Medina; LÚGARO, Eduardo Téllez. (Edit.). Encuentro de Etnohistoriadores. Santiago: Universidad de Chile, 1988. p. 7-9. (Série Nuevo Mundo: Cisco Siglos, n. 1). 
GRUPIONI, Luís Donisete Benzi. Livros didáticos e fontes de informações sobre as sociedades indígenas no Brasil. In: GRUPIONI, Luís Donisete Benzi; LOPES DA SILVA, Aracy (Orgs.). A temática indígena na escola. 4. ed. São Paulo: Global; Brasília: MEC JUNESCO, 2004. p. 481-526.

INSTITUTO BRASILEIRO DE GEOBRAFIA E ESTATÍ́STICA (IBGE). Tocantínia. População estimada 2016. Disponível em: <http://www.cidades.ibge.gov.br/xtras/perfil.php?lang=_EN \&codmun=172110\&search=| | infogr\%E1ficos:-informa\%E7\%F5es-completas $>$. Acesso em: 18 maio 2015.

INSTITUTO SOCIOAMBIENTAL (ISA). População indígena no Brasil. Povos indígenas no Brasil. [s.d]. Disponível em: <https://pib.socioambiental.org/pt/c/0/1/2/populacao-indigena-no-brasil>. Acesso em: 22 fev. 2017.

LE GOFF, Jacques. A história nova. In: LE GOFF, Jacques; CHARTIER, Roger; REVEL, Jacques (Org.). A história nova. 5. ed. São Paulo: Martins Fontes, 2005.

LÉVI-STRAUSS, Claude. Antropologia estrutural. 4. ed. Rio de Janeiro: Tempo Brasileiro, 1989.

. As estruturas elementares do parentesco. Petrópolis, RJ: Vozes, 1982.

LUCIANO BANIWA, Gersem José dos Santos. O índio brasileiro: o que você precisa saber sobre os povos indígenas no Brasil hoje. Brasília: MEC/UNESCO; LACED, 2006.

MELATTI, Júlio C. População Indígena. Série Antropologia, Brasília, n. 345, p. 1-39, 2004. . Índios do Brasil. 7. ed. São Paulo: Hucitec, 1994.

MONTEIRO, John M. Tupis, tapuias e historiadores. Estudos de História Indígena e do Indigenismo. 2001. 233 f. Tese (Livre-Docência)- Universidade de Campinas (UNICAMP), Departamento de Antropologia, Campinas, SP, 2001.

MONTEIRO, John M. Armas e armadilhas: história e resistência dos índios. In: NOVAES, Adauto (Org.). A outra margem do Ocidente. São Paulo: Cia das Letras, 1999. p. 237-49.

NIMUENDAJú, Curt. The Xerente. Los Angeles: L. A. Press, 1942.

NOLASCO, Genilson Rosa Severino. Rowahtuze Sinã: um estudo sobre a "pedagogia" Akwẽ e a sua relação com a escola indígena. Dissertação (Mestrado em Antropologia Social e Cultural)- Universidade de Coimbra, Coimbra, 2010.

OLIVEIRA E SILVA, Marcelo Gonçalves. Auwẽ Xavante: dos primeiros contatos ao confinamento territorial. Dissertação (Pós-Graduação em História)- Universidade de Brasília, Brasília, DF, 2013. 
OSSAMI DE MOURA, Marlene Castro Ossami de. Aldeamento Carretão: "marco zero" da história das relações étnicas dos Tapuios. Dimensões, Vitória, ES, n. 18, p. 29-48, 2006.

PERRONE-MOISÉS, Beatriz. Índios livres e índios escravos: os princípios da legislação indigenista do período colonial (séculos XVI a XVIII). In: CARNEIRO DA CUNHA, Manuela (Org.). História dos índios no Brasil. São Paulo: Cia da Letras; Secretaria Municipal de Cultura, 1992. p. 115-32.

PERROT, Michelle. Os excluídos da história. Rio de Janeiro: Paz e Terra, 1988.

POMIAN, Krzystof. A história das estruturas. In: LE GOFF, Jacques; CHARTIER, Roger; REVEL, Jacques. A história nova. 5. ed. São Paulo: Martins Fontes, 2005. p. 129-65.

QUIJANO, Anibal. Colonialidad del poder, eurocentrismo y América Latina. In: LANDER, Edgardo (Comp.). La colonialidad del saber: eurocentrismo y ciencias sociales. Perspectivas Latinoamericanas. Buenos Aires: Colección Sur Sur, CLACSO, 2005. p. 227-75.

REIS, José Carlos. As identidades do Brasil: de Varnhagen a FHC. 8. ed. Rio de Janeiro: Editora FGV, 2006.

RIBEIRO, Darcy. Os índios e a civilização: a integração das populações indígenas no Brasil. São Paulo: Cia das Letras, 1996.

SAHLINS, Marshall David. Metáforas históricas e realidades míticas: estrutura nos primórdios da história do reino Sandwich. Rio de Janeiro: Jorge Zahar Ed., 2008.

. Ilhas da história. Tradução de Bárbara Sette. Rio de Janeiro: Jorge Zahar Ed., 2003.

SANTILLI, Márcio. Os brasileiros e os índios. São Paulo: Editora Senac, 2000.

SAUSSURE, Ferdinand de. Curso de Lingüística Geral. 27. ed. São Paulo: Cultrix, 2006.

SCHWARCZ, Lilia K. Moritz. Questões de fronteira: sobre uma antropologia da história. Novos Estudos, São Paulo, n. 72, p. 119-35, jul. 2005.

SIBAKADI, Sílvia. Educação - Rowahtuze. In: WEWERING, Sílvia T. (Org.). Povo AkwẽXerente: vida, cultura e identidade. 2 ed. Belo Horizonte: Rona, 2012. p. 86-8.

SILVA, Cleube Alves da. Confrontando mundos: os Xerente, Xavante, Xakriabá e Akroá e os contatos com os conquistadores da Capitania de Goiás (1749-1851). Dissertação (Pós-Graduação em História) - Universidade Federal de Grande Dourados, Dourados, MS, 2006.

VAINFAS, Ronaldo. Colonização, miscigenação e questão racial: notas sobre equívocos e tabus da historiografia brasileira. Revista Tempo, Rio de Janeiro, n. 8, p. 1-12, ago. 1999. 
WÃKAINẼ, Vilmar. Direito à diferença. In: WEWERING, Silvia T. (Org.). Povo Akwẽ-Xerente: vida, cultura e identidade. 2. ed. Belo Horizonte: Rona, 2012. p. 82-3.

\section{Sobre os autores:}

Poliene Soares dos Santos Bicalho: Doutora em História Social pela Universidade de Brasília (UnB). Professora do Programa de Pós-Graduação Stricto sensu em Territórios e Expressões Culturais do Cerrado (TECCER) da Universidade Estadual de Goiás (UEG). Bolsista do Programa de Concessão de Bolsa de Incentivo ao Pesquisador (BIP). E-mail: poliene.soares@gmail.com

Márcia Machado: Doutora em Ciências Sociais pela Universidade de Brasília (UnB). Professora da Universidade Federal do Tocantins (UFT), Campus Universitário de Miracema. E-mail: marciamachado9@gmail.com

Recebido em 1을 de agosto de 2017

Aprovado para publicação em 25 de setembro de 2017 